\title{
Game Animal Density, Climate, and Tick-Borne Encephalitis in Finland, 2007-2017
}

Timothée Dub, Jukka Ollgren, Sari Huusko, Ruut Uusitalo, Mika Siljander, Olli Vapalahti, Jussi Sane

Tick-borne encephalitis (TBE) is an endemic infection of public health importance in Finland. We investigated the effect of ecologic factors on 2007-2017 TBE trends. We obtained domestic TBE case data from the National Infectious Diseases Register, weather data from the US National Oceanic and Atmospheric Administration, and data from the Natural Resources Institute in Finland on mammals killed by hunters yearly in game management areas. We performed a mixed-effects time-series analysis with time lags on weather and animal parameters, adding a random effect to game management areas. During 2007-2017, a total of 395/460 (86\%) domestic TBE cases were reported with known place of exposure and date of sampling. Overall, we found that TBE incidence increased yearly by $15 \%$. After adjusting for the density of other animals and minimum temperatures, TBE incidence was positively associated with white-tailed deer density. Variation in host animal density should be considered when assessing TBE risks and designing interventions.

7 ick-borne encephalitis (TBE) is an endemic vec1 torborne infectious disease of public health importance in Finland. It is caused by tick-borne encephalitis virus (TBEV), a member of the Flavivirus genus of the Flaviviridae family. TBEV has 5 subtypes: European and Siberian subtypes, whose presence in Finland has been established $(1,2)$; recently described Himalayan subtype; Far Eastern subtype (3); and Baikalian subtype (4). TBEV is most often transmitted through the bite of Ixodes ricinus or $I$. persulcatus ticks, 2 species found in Finland that can carry both the European and Siberian TBEV subtypes (5-7). TBEV may also be transmitted through

Author affiliations: European Programme for Intervention

Epidemiology Training, European Centre for Disease

Prevention and Control, Stockholm, Sweden (T. Dub); Finnish

institute for Health and Welfare, Helsinki, Finland (T. Dub,

J. Ollgren, S. Huusko, J. Sane); University of Helsinki, Helsinki

(R. Uusitalo, M. Siljander, O. Vapalahti); Helsinki University

Hospital, Helsinki (O. Vapalahti)

DOI: https://doi.org/10.3201/eid2612.191282 the consumption of unpasteurized dairy products from infected livestock $(8,9)$.

Most TBEV infections are asymptomatic (10). For clinical infections, the infectious course will differ depending on the TBEV subtype. The European subtype is typically responsible for a biphasic course of the disease: a short incubation period leads to a viremic phase associated with influenza-like symptoms, followed by an asymptomatic interval before onset of acute viral meningoencephalitis. Residual sequelae are reported in up to $50 \%$ of patients with European subtype TBE; the case fatality rate (CFR) is $<2 \%(10,11)$. The Siberian subtype is associated with direct neurologic signs including focal encephalitis or meningitis in most symptomatic cases and complete recovery occurring in $80 \%$ patients; CFR approaches $2 \%$ (10). Effective TBE vaccines based on purified, formalin-inactivated TBEV are available, but several doses and boosters are required to acquire and maintain immunity.

In Europe, several thousand TBE cases are reported yearly, with the highest incidences in the Baltic countries $(12,13)$. In Finland, TBE cases are reported from relatively restricted areas, mostly around the archipelago and the coast (14). During 1995-2013, the average annual number of cases was 25 , ranging from 5 to 43 cases per year (14), but the incidence has increased over the past 5 years with the development of new TBE foci (15).

Several seasonal or environmental factors, such as temperature $(16,17)$ and humidity $(18)$, along with the number of animal hosts for ticks feeding (19), have been shown to affect tick life cycles and activity, which in turn have been associated with transmission of tick-borne infections, such as Lyme disease $(18,20,21)$ and TBE $(21-24)$. Our aim was to assess the effects of environmental factors, game animal density, and temperatures on TBE emergence and distribution in Finland and to use these findings to inform risk assessment and prevention strategies. 


\section{Methods}

\section{Epidemiologic Data}

In Finland, TBE is reportable to the National Infectious Diseases Register (NIDR), maintained by the Finnish Institute for Health and Welfare (Terveyden ja hyvinvoinnin laitos [THL]). An acute laboratory-confirmed TBE case is defined as one in which a patient without a disease-specific medical history (e.g., no previous TBEV exposure) has coherent central nervous system symptomatology, such as meningitis, meningoencephalitis, or encephalomyelitis, and TBEV-specific IgM and IgG detected in either cerebrospinal fluid or serum. Two clinical laboratories in Finland perform TBE diagnostics and report results electronically to the NIDR. Each notification includes the specimen date and the patient's unique national identity code, date of birth, sex, and place of residence.

Since 2007, the Finnish Institute for Health and Welfare has enhanced TBE surveillance in place; because of these additional data, we were able to examine medical records and interview patients to determine the most likely places of exposure (25). From these sources, we extracted data on the number of TBE cases for 2007-2017. To account for a median TBE incubation period of $\approx 7-14$ (range 4-28) days (10), suspected date of exposure was calculated as 2 weeks before date of symptom onset or 3 weeks before date of sampling if date of onset was unknown.

\section{Weather and Game Animal Density Data}

We retrieved temperature data from daily weather reports from multiple meteorologic stations in Finland using the United States National Oceanographic and Atmospheric Administration (NOAA) Climate Data Online open-access platform (https:/ / www.ncdc.noaa. gov/cdo-web) (26). Including geographic coordinates for each station, we used QGIS 2.14.20-Essen version software (QGIS, https://qgis.org/en/site) to assign each station to its respective game management area and used Stata version 15 statistical software (StataCorp, https://www.stata.com) to calculate weather data for each game management area $(n=16)$. We used the difference between reported minimum and maximum daily temperatures to determine temperature variation, then calculated monthly mean values for minimum, maximum, average, and variation for each weather station. We used these data to calculate mean temperature values for the game management areas.

We used mean daily temperature values from each game management area to calculate 2 other weather parameters that affect tick populations. We used the proportion of days in a month with a mean temperature $>5^{\circ} \mathrm{C}$ because ticks are commonly encountered in the northern regions of Europe at that temperature level $(27,28)$. We used monthly mean temperature surplus (mean temperature in degrees Celsius above $9^{\circ} \mathrm{C}$ (or 0 , if $\leq 9^{\circ} \mathrm{C}$ ) because it has been observed that Ixodes ricinus larval activity and development occurs at that temperature (29).

For the spatial unit in our study, we used game management areas as defined by the Natural Resources Institute Finland. We obtained data for 20062017 on the number of animals killed by hunters in game management areas for moose (Alces alces), fallow deer (Dama dama), roe deer (Capreolus capreolus), white-tailed deer (Odocoileus virginianus), European hare (Lepus europaeus), mountain hare (Lepus timidus), and red fox (Vulpes vulpes) from the statistical services portal of the Natural Resources Institute Finland (Luonnonvarakeskus [Luke]) (30). We used these data on the numbers of animals killed by hunters as a proxy for actual animal density because they have been shown to be strongly correlated $(31,32)$. To improve readability of our results, we divided the number of animals killed by hunters per game management areas by 100 (e.g., 5,500 animals $=5.5$ ) and used this number in our models. We used a 1-year lag to estimate the level of TBE incidence based its demonstrated correlation with calculated animal density (22).

\section{Statistical Analysis}

We calculated the monthly number of cases and temperature values for each game management area, then modeled annual TBE incidence in 2007-2017 at a national level and by game management area using negative binomial regressions, a type of generalized linear model used to model overdispersed count data. As our core model for this time-series analysis, we fit a mixed-effects negative binomial regression model with the monthly numbers of TBE cases reported from each game management area as an outcome and year-month unit $(2010 \mathrm{~m} 1,2010 \mathrm{~m} 2$, etc.), adjusted for a 12-month periodicity as explanatory variables, with a random effect on game management areas to account for regional variability.

For calculations, all temperature variables were used with a 1-month lag period, assuming that ticks would not become fully active again from the beginning of periods with optimal life cycle temperature ranges. By adding the variables to the core model one at a time, we determined the model that showed the best Akaike information criterion/Bayesian information criterion combination. The climatic predictor that offered the best fit was considered the most informative predictor, and we then used it as an adjustment 
variable when modeling the effect of the number of animals killed on TBE incidence for each game management area. We then conducted single-variable analyses of all animal density parameters per 100 units, with a 1-year lag.

Finally, we used stepwise backward selection to develop a final multiple-variable analysis model to determine the effect of animal density on TBE incidence in a multilevel mixed-effects negative binomial regression with a random effect on game management areas. We assessed the distribution of Pearson and Deviance residuals and looked for autocorrelation of residuals. Statistical significance was considered at a 5\% level. We used Stata to perform modelling; results were displayed with incidence ratios (IR) to 2 decimal places with $95 \%$ CIs and, when relevant, negative binomial regression coefficients before exponentiation to 3 decimal places with 95\% CIs.

\section{Results}

\section{Epidemiology of TBE Cases}

During 2007-2017, a total of 488 cases were reported to NIDR, including $28(6 \%)$ with reported exposure in a foreign country (Estonia, 18; Sweden, 5; Russia, 2; other, 3 ) and 65 cases $(13 \%)$ without known place of exposure or date of sampling. We included in the analysis the remaining 395 (81\%) cases of domestic TBE reported to NIDR. Median yearly number of cases was 28 (interquartile range [IQR] 20-50). Over the study period, the median number of cases was 7 per management area, ranging from 0 in several central game management areas to 120 cases in southern Finland (Varsinais-Suomi) (Figure 1). Overall, nationwide domestic TBE incidence significantly increased by $15 \%$ (IR 1.15; 95\% CI 1.10-1.20) yearly, with regional variation (Table 1 ).

\section{Association of TBE Incidence with Game Animal Density and Weather-Based Parameters}

We used data from 174 different weather stations in total; the number of stations assigned to each game management area ranged from 3 in the Aland Islands to 47 in the Lappi (Lapland) game management area (Appendix Table 1, https:/ / wwwnc.cdc. gov/EID/article/26/12/19-1282-App1.pdf). The median number of daily reports available per station per month was 30 (IQR 30-31). The number of animals killed by hunters by area was available on a yearly level for all game management areas except for the Alland Islands because the Natural Resources Institute Finland did not collect data for this management area.
Our core mixed-effects negative binomial regression showed a 1\% monthly increase (IR 1.01 [1.011.01]; coefficient 0.011 [0.008-0.149]) and a significant 12 -month periodicity $(\mathrm{p}<0.001)$. None of the temperature variables showed a significant association with monthly TBE incidence (Table 2). The lowest Akaike information criterion/Bayesian information criterion combination was seen for monthly average minimum temperature; therefore, we adjusted our modeling of hunting data for this weather parameter.

Because data on mammals killed by hunters were not available for the Åland Islands game management area, our analysis was restricted to 15 of the 16 game management areas (Appendix Table 2). Our single hunting data variable analysis, using a mixed-effects negative binomial regression, adjusted for yearmonth time unit, average minimum temperature, periodicity, and a random effect on game management areas, showed no significant results (Appendix Table 3). The numbers of moose, roe deer, and fallow deer were negatively associated with TBE incidence trends; numbers of fox, white-tailed deer, European hare, and mountain hare were positively associated with TBE incidence trends, although not significantly.

Using a stepwise approach for our analysis of the effect of several animal densities adjusted for average monthly minimum temperature, we obtained a model containing the numbers of moose, roe deer, white-tailed deer, mountain hare, and fox killed by hunters (Appendix Table 4). We found that TBE incidence was positively associated with the number of white-tailed deer killed by hunters (IR 1.04 [1.01-1.07]; coefficient 0.037 [0.009-0.064]), but it was significantly negatively associated with the number of roe deer $(\mathrm{IR}=0.94$ [0.88-1.00]; coefficient -0.067 [ -0.131 to -0.003$]$ ). Other animal densities yielded no significant results (Table 3); Pearson and deviance residuals were normally distributed around 0 , and residuals only showed autocorrelation in 2 game management areas out of 14 included in the model.

Figure 2 presents the actual monthly number of TBE cases and the model's prediction for the 4 game management areas included the model that contributed the most to TBE incidence: Varsinais-Suomi, Kaakkois-Suomi, Uusimaa, and Lappi. These results show that our model failed to predict some incidence peaks; however, the yearly average difference between the actual number of cases and the model's prediction was 0.04, ranging from -0.05 in Etela Hame to 0.19 in Uusimaa.

\section{Discussion}

During 2007-2017, TBE incidence in Finland increased yearly by $15 \%$. Our analysis did not find a statistically 


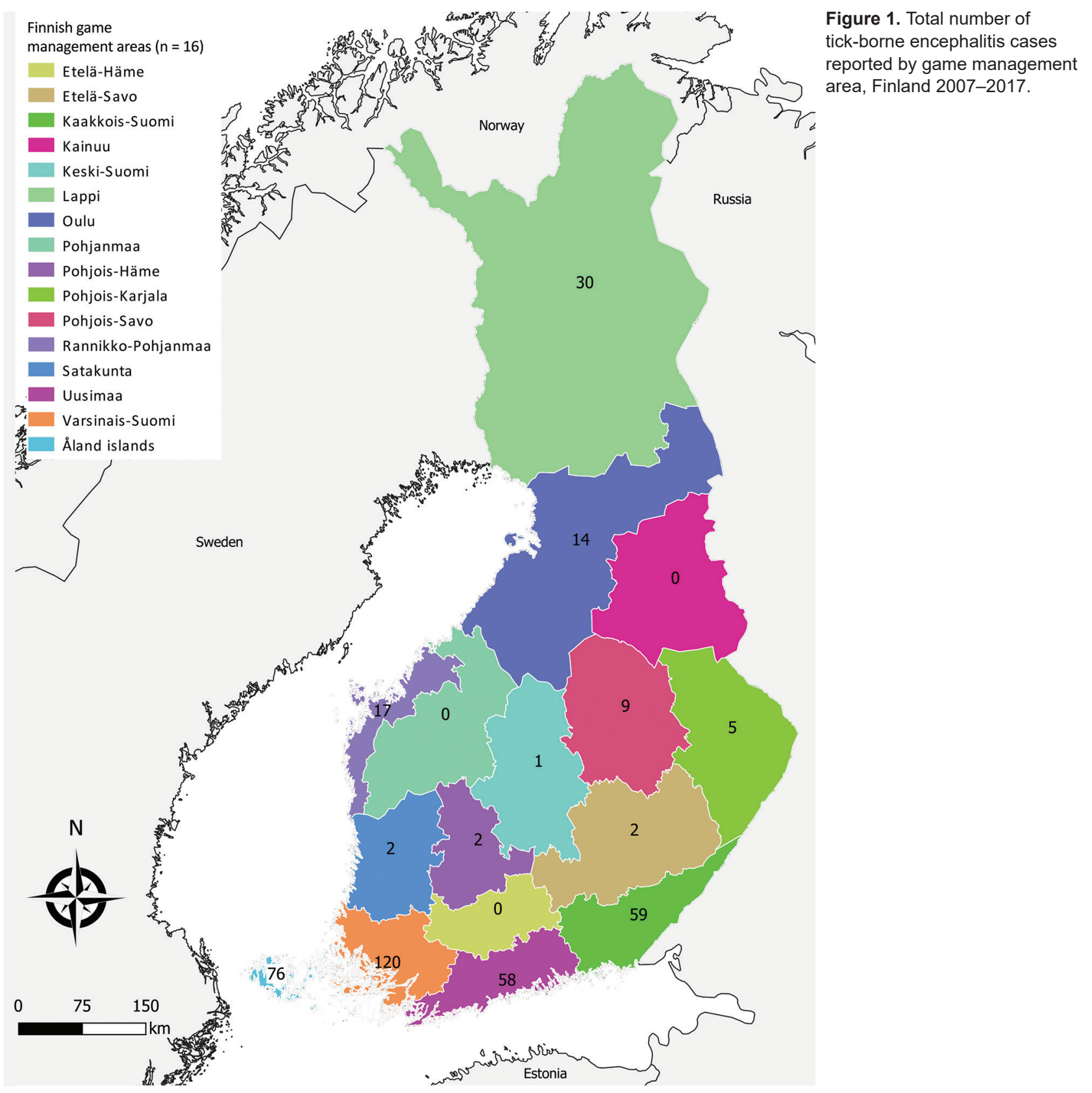

significant association between temperature and TBE incidence. Multivariable analysis of the effect of several animal densities showed that TBE incidence was positively associated with the number of white-tailed deer, but an increase in the number of roe deer killed by hunters led to a decrease in TBE incidence. Our study provides further evidence on the importance of wildlife in the epidemiology of TBE. Blood meals are necessary for 3 different stages of tick development; large mammals such as deer can both serve as transmission hosts and provide blood meals to ticks, and their numbers can therefore have a strong influence on TBE rates (22).
The results of our analysis of weather data were not consistent with those in many other studies on the effect of changes in temperature on TBE incidence $(22,33,34)$. Regarding animal data, our results were partly in line with a 2017 study conducted in Sweden in which single-variable analysis with a 1-year lag showed that the number of fallow deer and moose killed by hunters were negatively associated with TBE incidence, but contrary to our findings, the number of roe deer had a positive effect on TBE increase (22). Roe deer abundance is a parameter that has previously been associated with TBE incidence in other 
Tick-Borne Encephalitis in Finland

Table 1. Yearly tick-borne encephalitis incidence increase nationwide and by game management area, Finland 2007-2017

\begin{tabular}{|c|c|c|c|c|c|}
\hline Game management area & $\begin{array}{c}\text { Median annual no. } \\
\text { cases (IQR)† }\end{array}$ & Annual no. cases, range & IR $(95 \% \mathrm{Cl})$ & $p$ value & Yearly trend, \% \\
\hline Åland islands & $7(2-11)$ & $1-14$ & $0.97(0.85-1.10)$ & 0.60 & $-3 \%$ \\
\hline Etelä-Häme & None reported & $0-0$ & & & \\
\hline Etelä-Savo & $0(0-0)$ & $0-1$ & $1.17(0.73-1.87)$ & 0.51 & $+17 \%$ \\
\hline Kaakkois-Suomi & $5(2-6)$ & $1-15$ & $1.28(1.04-1.32)$ & $<0.01$ & $+28 \%$ \\
\hline Kainuu & None reported & $0-0$ & & & \\
\hline Keski-Suomi & $0(0-0)$ & $0-1$ & $1.46(0.61-3.52)$ & 0.40 & $+46 \%$ \\
\hline Lappi & $2(1-3)$ & $0-9$ & $1.23(1.08-1.40)$ & $<0.01$ & $+23 \%$ \\
\hline Oulu & $0(0-3)$ & $0-4$ & $1.50(1.18-1.92)$ & 0.001 & $+50 \%$ \\
\hline Pohjanmaa & None reported & $0-0$ & & & \\
\hline Pohjois-Häme & $0(0-0)$ & $0-2$ & $1.34(0.31-5.80)$ & 0.70 & $+34 \%$ \\
\hline Pohjois-Karjala & $0(0-1)$ & $0-1$ & $1.21(0.89-1.65)$ & 0.22 & $+21 \%$ \\
\hline Pohjois-Savo & $0(0-2)$ & $0-3$ & $1.21(0.96-1.53)$ & 0.11 & $+21 \%$ \\
\hline Rannikko-Pohjanmaa & $1(0-2)$ & $0-6$ & $0.80(0.65-1.00)$ & 0.05 & $-20 \%$ \\
\hline Satakunta & $0(0-0)$ & $0-1$ & $3.00(0.60-14.87)$ & 0.18 & $+200 \%$ \\
\hline Uusimaa & $4(1-9)$ & $0-16$ & $1.39(1.25-1.54)$ & 0.001 & $+39 \%$ \\
\hline Varsinais-Suomi & $7(4-17)$ & $3-28$ & $1.23(1.15-1.31)$ & 0.001 & $+23 \%$ \\
\hline Finland & $28(20-50)$ & $17-73$ & $1.15(1.10-1.20)$ & 0.001 & $+15 \%$ \\
\hline
\end{tabular}

${ }^{*} \mathrm{IQR}$, interquartile range; IR, incidence ratio.

$\dagger$ None reported indicates that 0 cases were reported in that management area over the entire study period.

TBE endemic areas. In northern Italy, it was shown that roe deer density was higher in areas where more TBE cases were detected (23); however, in Slovenia, when both red deer and roe deer density were studied, only red deer density showed a significant positive association with TBE incidence (24). Similarly, in the Czech Republic, in a multivariable model adjusted for forest and agriculture area, only the number of wild boars killed by hunters had a significant positive association with TBE incidence, whereas roe deer density was negatively, but nonsignificantly, associated with TBE incidence (35). However, the results of these studies cannot all be properly compared with the findings from our work due to different methodologies, fauna, the presence in Finland of 2 tick species (Ixodes ricinus and I. persulcatus) capable of transmitting TBEV, and differing temperature and environmental characteristics. For example, a study similar to ours was recently conducted in Sweden, a neighboring country with similar climate and fauna, but the species of deer studied differed (22).

White-tailed deer are nonnative in Finland, introduced by the mid-20th century; the species' numbers have grown from fewer than 10 to several hundred thousand $(36,37)$. A geospatial modeling study us- ing similar data recently showed that in Finland, the density of this animal was correlated with concurrent incidence rates of TBE (38), which is in line with our findings. These known ticks (I. ricinus and I. persulcatus) (39) and the TBE host (40) were also introduced in the Czech Republic (41), another TBE-endemic country; however, to our knowledge, their effect on incidence trends there has not been studied.

As in any ecologic study, our results have to be interpreted with caution and should not be generalized to an individual level; some unmeasured characteristics might also differ between game management areas (42). In addition, we identified several limitations to our work. First, because we had to use average values for large geographic areas (median area size $19,185 \mathrm{~km}^{2}$ [IQR 15,826-21,589 $\mathrm{km}^{2}$ ]), the effect of temperatures on TBE incidence might have been diluted, which would explain why in our analysis, an increase in temperature was not linked to an incidence increase. This effect would also apply for animal density, which may vary within a game management area. Second, we were not able to use precipitation levels, a parameter with a known influence on tick lifecycle and activity, because data were not collected in a systematic manner throughout Finland.

\begin{tabular}{|c|c|c|c|c|c|}
\hline Weather parameters $\dagger$ & Coefficient (95\% Cl of coefficient) & $\operatorname{IR}(95 \% \mathrm{Cl})$ & $p$ value & $\mathrm{AIC}$ & $\mathrm{BIC}$ \\
\hline Monthly average minimum temperature & $-0.069(-0.145$ to 0.08$)$ & $0.93(0.87-1.01)$ & 0.08 & $1,263.0$ & $1,302.6$ \\
\hline Monthly average mean temperature & $-0.070(-0.149$ to 0.008$)$ & $0.93(0.86-1.01)$ & 0.08 & $1,263.1$ & $1,302.6$ \\
\hline Monthly average maximum temperature & $-0.056(-0.126$ to 0.013$)$ & $0.95(0.88-1.01)$ & 0.11 & $1,263.6$ & $1,303.1$ \\
\hline Monthly average of daily temperature variation & $0.000(-0.103$ to 0.104$)$ & $1.00(0.90-1.11)$ & 0.99 & $1,266.1$ & $1,305.6$ \\
\hline $\begin{array}{l}\text { Proportion of days in a month with a mean } \\
\text { temperature }>5^{\circ} \mathrm{C}\end{array}$ & $-0.718(-1.702$ to 0.265$)$ & $0.49(0.18-1.30)$ & 0.15 & $1,264.1$ & $1,303.6$ \\
\hline Monthly average of mean temperature surplusł & $-0.057(-0.135$ to 0.021$)$ & $0.94(0.87-1.02)$ & 0.15 & $1,264.0$ & $1,303.6$ \\
\hline
\end{tabular}

Monthly average of mean temperature surplus $-0.057(-0.135$ to 0.021$)$

${ }^{*} \mathrm{AIC}$, Akaike information criterion; BIC, Bayesian information criterion; IR, incidence ratio.

†Adjusted for trend over time and 12 mo periodicity.

‡Temperature surplus: mean temperature minus $9^{\circ} \mathrm{C}$ if $\geq 9^{\circ} \mathrm{C}$, otherwise 0 . 
Third, because animal density per game management areas was not available, we used data on animals killed by hunters. Even though these data have been used by several researchers in similar studies on TBE (22) and Lyme disease, another tick-borne zoonotic disease (20), we cannot assume that it perfectly reflects animal density variations. The reported number of animals killed by hunters can also be affected by changes in hunting habits and wildlife population control regulations. Finally, the effect of density of other potential hosts of ticks and TBEV, such as smaller animals (e.g., rodents), could not be investigated because of lack of available data in Finland. The absence of data on precipitation levels and small rodent

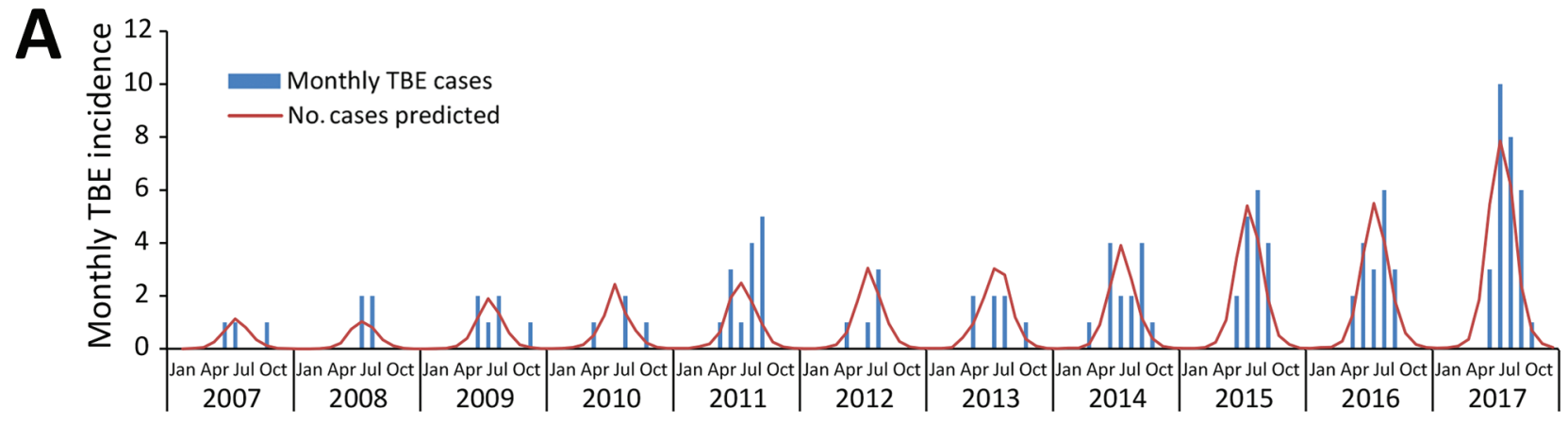

B

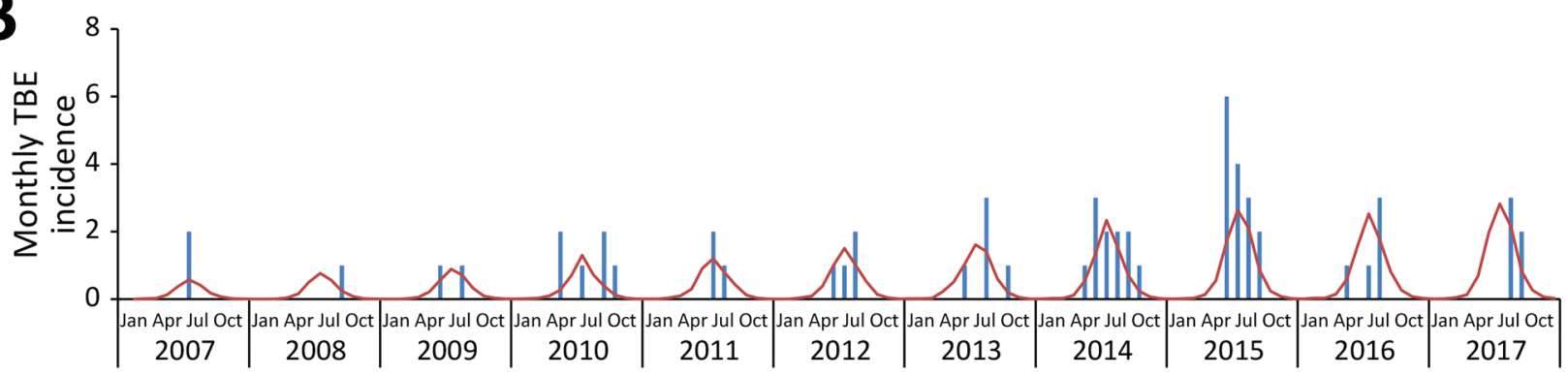

C

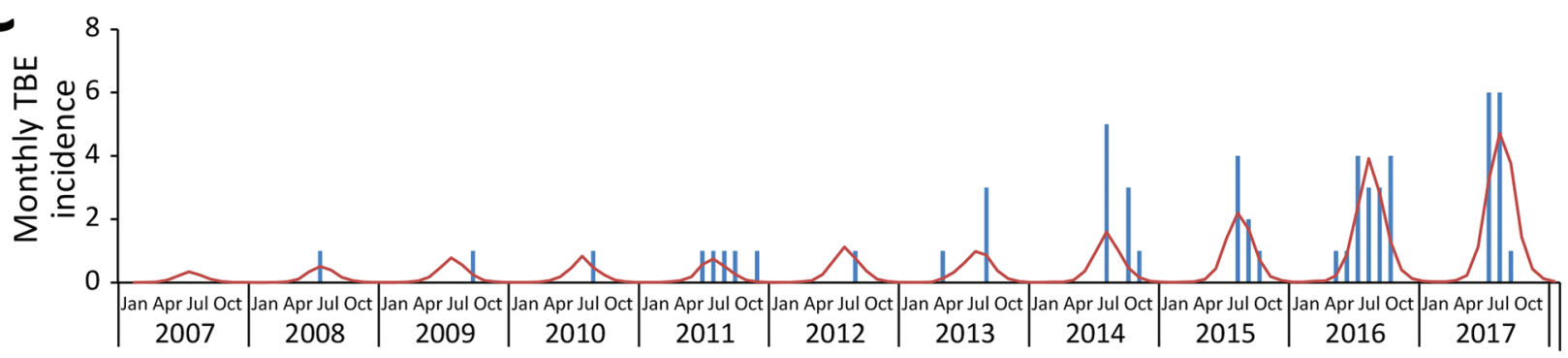

D

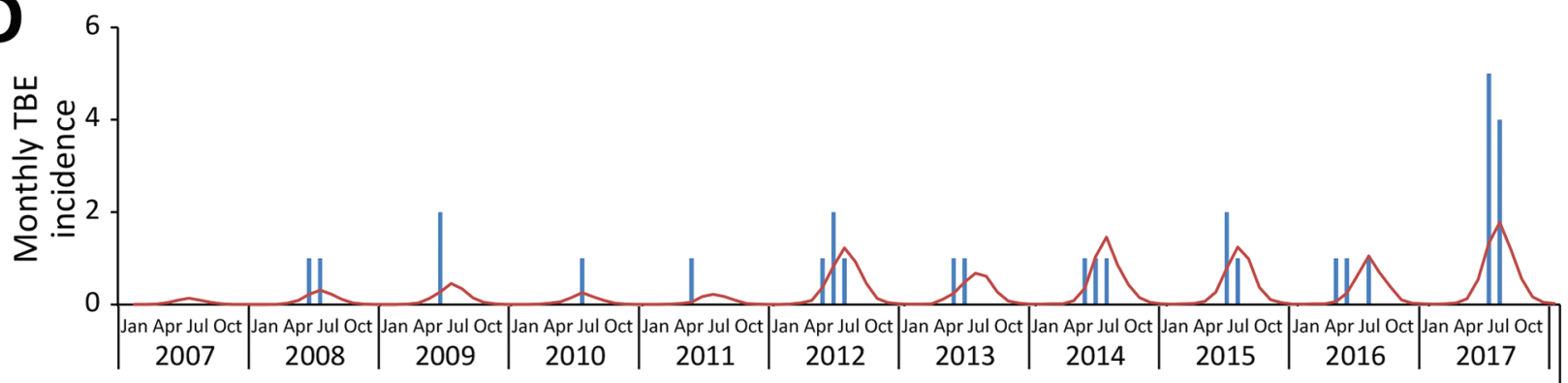

Figure 2. Actual and predicted number of TBE cases in 4 game management areas, Finland, 2007-2017. A) Varsinais-Suomi; B) KaakkoisSuomi; C) Uusimaa; and D) Lappi. Number of tick-borne encephalitis cases is predicted by a mixed effects multivariable negative binomial model including number of moose, roe deer, white-tailed deer, mountain hare, and red fox killed by hunters adjusted for a 12-month periodicity, minimum temperature, and month, with a random effect on game management areas. TBE, tick-borne encephalitis 
Tick-Borne Encephalitis in Finland

Table 3. Ecologic parameters associated with tick-borne encephalitis incidence, Finland, 2007-2017*

\begin{tabular}{|c|c|c|c|c|c|}
\hline Species & Coefficient (95\% Cl of coefficient) & IR $(95 \% \mathrm{Cl})$ & $p$ value & $\mathrm{AIC}$ & $\mathrm{BIC}$ \\
\hline Moose (Alces alces) & $-0.011(-0.025$ to 0.002$)$ & $0.99(0.98-1.00)$ & 0.11 & 1034.1 & 1101.1 \\
\hline Roe deer (Capreolus capreolus) & $-0.067(-0.131$ to -0.003$)$ & $0.94(0.88-1.00)$ & 0.04 & & \\
\hline White-tailed deer (Odocoileus virginianus) & $0.037(0.009-0.064)$ & $1.04(1.01-1.07)$ & 0.01 & & \\
\hline Mountain hare (Lepus timidus) & $0.004(-0.000$ to 0.008$)$ & $1.00(1.00-1.01)$ & 0.08 & & \\
\hline Red fox (Vulpes vulpes) & $0.007(-0.001$ to 0.015$)$ & $1.01(1.00-1.02)$ & 0.09 & & \\
\hline
\end{tabular}

density might partially explain why our model failed to properly predict several sudden increases, such as in Varsinais-Suomi in 2017, Kaakkois-Suomi in 2015, or over the final years of the study period in the Uusimaa and Lappi game management areas (Figure 2).

The effect of environmental factors, including climate change and host animal density variations, on vectorborne diseases is a growing concern in Finland. Therefore, over the coming years, the Finnish Institute for Health and Welfare will participate in a national consortium to quantify factors driving vectorborne diseases. The project will use modern analysis tools, empirical field studies, and predictive spatiotemporal modeling to provide information for intervention strategies integrating data on human disease incidence, dynamics of host communities, and vectors and environmental variables, including climate (43). We hope this project will lead to better knowledge about the extent and effects of climate change and milder temperatures and the influence of certain animal hosts on TBE incidence because it is growing in the European region $(12,13)$. The findings of our study, especially that white-tailed deer density is associated with the incidence rates of TBE, show that variations in host animal density should be taken into account when assessing regional TBE risk, forecasting future trends, and designing interventions. Experimental studies on reducing or restricting the movement of deer populations (with fences) should assess whether such interventions can be effective to control tick populations and decrease TBE incidence.

\section{About the Author}

Dr. Timothée Dub is a European Programme for Intervention Epidemiology Training (EPIET) fellow based at the Finnish Institute for Health and Welfare in Helsinki, Finland. He has been involved in various projects on vectorborne disease epidemiology.

\section{References}

1. Jääskeläinen AE, Tikkakoski T, Uzcátegui NY, Alekseev AN, Vaheri A, Vapalahti O. Siberian subtype tickborne encephalitis virus, Finland. Emerg Infect Dis. 2006;12:156871. https:// doi.org/10.3201/eid1210.060320
2. Jääskeläinen AE, Sironen T, Murueva GB, Subbotina N, Alekseev AN, Castrén J, et al. Tick-borne encephalitis virus in ticks in Finland, Russian Karelia and Buryatia. J Gen Virol. 2010;91:2706-12. https:// doi.org/10.1099/vir.0.023663-0

3. Dai X, Shang G, Lu S, Yang J, Xu J. A new subtype of eastern tick-borne encephalitis virus discovered in Qinghai-Tibet Plateau, China. Emerg Microbes Infect. 2018;7:1-9. https://doi.org/10.1038/s41426-018-0081-6

4. Kovalev SY, Mukhacheva TA. Reconsidering the classification of tick-borne encephalitis virus within the Siberian subtype gives new insights into its evolutionary history. Infect Genet Evol. 2017;55:159-65. https:/ / doi.org/ 10.1016/j.meegid.2017.09.014

5. Laaksonen M, Sajanti E, Sormunen JJ, Penttinen R, Hänninen J, Ruohomäki K, et al. Crowdsourcing-based nationwide tick collection reveals the distribution of Ixodes ricinus and I. persulcatus and associated pathogens in Finland. Emerg Microbes Infect. 2017;6:e31. https:/ / doi.org/10.1038/ emi.2017.17

6. Jääskeläinen A, Tonteri E, Pieninkeroinen I, Sironen T, Voutilainen L, Kuusi M, et al. Siberian subtype tick-borne encephalitis virus in Ixodes ricinus in a newly emerged focus, Finland. Ticks Tick Borne Dis. 2016;7:216-23. https://doi.org/10.1016/j.ttbdis.2015.10.013

7. Jääskeläinen AE, Tonteri E, Sironen T, Pakarinen L, Vaheri A, Vapalahti O. European subtype tick-borne encephalitis virus in Ixodes persulcatus ticks. Emerg Infect Dis. 2011;17:323-5. https://doi.org/10.3201/eid1702.101487

8. Offerdahl DK, Clancy NG, Bloom ME. Stability of a tick-borne flavivirus in milk. Front Bioeng Biotechnol. 2016;4:40. https://doi.org/10.3389/fbioe.2016.00040

9. Labuda M, Elecková E, Licková M, Sabó A. Tick-borne encephalitis virus foci in Slovakia. Int J Med Microbiol. 2002;291(Suppl 33):43-7. https:/ / doi.org/10.1016/ S1438-4221(02)80008-X

10. Růžek D, Dobler G, Donoso Mantke O. Tick-borne encephalitis: pathogenesis and clinical implications. Travel Med Infect Dis. 2010;8:223-32. https:/ / doi.org/10.1016/ j.tmaid.2010.06.004

11. Kaiser R. The clinical and epidemiological profile of tick-borne encephalitis in southern Germany 1994-98: a prospective study of 656 patients. Brain. 1999;122:2067-78. https:/ / doi.org/10.1093/brain/122.11.2067

12. European Centre for Disease Prevention and Control. Tick-borne encephalitis. Annual epidemiological report for 2016. Stockholm: The Centre; 2018.

13. Beauté J, Spiteri G, Warns-Petit E, Zeller H. Tick-borne encephalitis in Europe, 2012 to 2016. Euro Surveill. 2018;23:pii=1800201. https:/ / doi.org/10.2807/1560-7917. ES.2018.23.45.1800201

14. Tonteri E, Kurkela S, Timonen S, Manni T, Vuorinen T, Kuusi M, et al. Surveillance of endemic foci of tick-borne encephalitis in Finland 1995-2013: evidence of emergence of new foci. Euro Surveill 2015;20:pii=30020. https:/ / doi. org/10.2807/1560-7917.ES.2015.20.37.30020 
15. Smura T, Tonteri E, Jääskeläinen A, von Troil G, Kuivanen S, Huitu $\mathrm{O}$, et al. Recent establishment of tick-borne encephalitis foci with distinct viral lineages in the Helsinki area, Finland. Emerg Microbes Infect. 2019;8:675-83. https://doi.org/10.1080/22221751.2019.1612279

16. Hancock PA, Brackley R, Palmer SCF. Modelling the effect of temperature variation on the seasonal dynamics of Ixodes ricinus tick populations. Int J Parasitol. 2011;41:513-22. https://doi.org/10.1016/j.ijpara.2010.12.012

17. Randolph SE, Green RM, Peacey MF, Rogers DJ. Seasonal synchrony: the key to tick-borne encephalitis foci identified by satellite data. Parasitology. 2000;121:15-23. https://doi. org/10.1017/S0031182099006083

18. Brownstein JS, Holford TR, Fish D. A climate-based model predicts the spatial distribution of the Lyme disease vector Ixodes scapularis in the United States. Environ Health Perspect. 2003;111:1152-7. https:/ / doi.org/10.1289/ehp.6052

19. Estrada-Peña A, de la Fuente J. The ecology of ticks and epidemiology of tick-borne viral diseases. Antiviral Res. 2014;108:104-28. https://doi.org/10.1016/ j.antiviral.2014.05.016

20. Ostfeld RS, Canham CD, Oggenfuss K, Winchcombe RJ, Keesing F. Climate, deer, rodents, and acorns as determinants of variation in Lyme-disease risk. PLoS Biol. 2006;4:e145. https:// doi.org/10.1371/journal.pbio.0040145

21. Tkadlec E, Václavík T, Široký P. Rodent host abundance and climate variability as predictors of tickborne disease risk 1 year in advance. Emerg Infect Dis. 2019;25:1738-41. https://doi.org/10.3201/eid2509.190684

22. Jaenson TGT, Petersson EH, Jaenson DGE, Kindberg J, Pettersson JH-O, Hjertqvist $\mathrm{M}$, et al. The importance of wildlife in the ecology and epidemiology of the TBE virus in Sweden: incidence of human TBE correlates with abundance of deer and hares. Parasit Vectors. 2018;11:477. https:/ / doi.org/10.1186/s13071-018-3057-4

23. Rizzoli A, Hauffe HC, Tagliapietra V, Neteler M, Rosà R. Forest structure and roe deer abundance predict tick-borne encephalitis risk in Italy. PLoS One. 2009;4:e4336. https://doi.org/10.1371/journal.pone.0004336

24. Knap N, Avšič-Županc T. Correlation of TBE incidence with red deer and roe deer abundance in Slovenia. PLoS One. 2013;8:e66380. https:// doi.org/10.1371/journal. pone. 0066380

25. Finnish Institute for Health and Welfare. Finnish National Infectious Diseases Register [cited 2017 Dec 22]. https://thl.fi/en/web/infectious-diseases-andvaccinations/surveillance-and-registers/finnish-nationalinfectious-diseases-register

26. National Oceanic and Atmospheric Administration. National Centers for Environmental Information. Climate data online. National Climatic Data Center [cited 2019 Apr 26]. https://www.ncdc.noaa.gov/cdo-web

27. Jaenson TGT, Eisen L, Comstedt P, Mejlon HA, Lindgren E, Bergström S, et al. Risk indicators for the tick Ixodes ricinus and Borrelia burgdorferi sensu lato in Sweden. Med Vet Entomol. 2009;23:226-37. https://doi.org/10.1111/ j.1365-2915.2009.00813.x

28. Jaenson TGT, Lindgren E. The range of Ixodes ricinus and the risk of contracting Lyme borreliosis will increase northwards when the vegetation period becomes longer. Ticks Tick Borne Dis. 2011;2:44-9. https://doi.org/10.1016/ j.ttbdis.2010.10.006

29. Daniel M, Malý M, Danielová V, Kříž B, Nuttall P. Abiotic predictors and annual seasonal dynamics of Ixodes ricinus, the major disease vector of Central Europe. Parasit Vectors. 2015;8:478. https://doi.org/10.1186/s13071-015-1092-y
30. National Resources Institute Finland (Luke). Luke's statistical services [cited 2019 Apr 26]. https:/ / stat.luke.fi/ en/uusi-etusivu

31. Andrén H, Liberg O. Final report: the lynx project [in Swedish]. Riddarhyttan: Grimsö Research Station, Department of Ecology, Swedish University of Agricultural Sciences; 2008. p. 44.

32. Cattadori IM, Haydon DT, Thirgood SJ, Hudson PJ. Are indirect measures of abundance a useful index of population density? The case of red grouse harvesting.Oikos. 2003; 100:439-46. https://doi.org/10.1034/j.1600-0706.2003.12072.x

33. Tokarevich N, Tronin A, Gnativ B, Revich B, Blinova O, Evengard B. Impact of air temperature variation on the ixodid ticks habitat and tick-borne encephalitis incidence in the Russian Arctic: the case of the Komi Republic. Int J Circumpolar Health. 2017;76:1298882. https:/ / doi.org/ 10.1080/22423982.2017.1298882

34. Czupryna P, Moniuszko A, Pancewicz S, Zajkowska O, Garkowski A, Grygorczuk S, et al. Influence of climatic, demographic and socioeconomic factors on tick-borne encephalitis incidence in 6 counties of Podlaskie region in 1994-2014. Przegl Epidemiol. 2016;70:21-5, 111-4.

35. Kriz B, Daniel M, Benes C, Maly M. The role of game (wild boar and roe deer) in the spread of tick-borne encephalitis in the Czech Republic. Vector Borne Zoonotic Dis. 2014;14:8017. https://doi.org/10.1089/vbz.2013.1569

36. Yle Uutiset. White-tailed deer in Finland: from 5 to 100,000 in 80 years. 2018 [cited 2019 May 6]. https://yle.fi/ uutiset/osasto/news/white-tailed_deer_in_finland_from_5_ to_100000_in_80_years/10294577

37. Kekkonen J, Wikström M, Ala-Ajos I, Lappalainen V, Brommer JE. Growth and age structure in an introduced and hunted cervid population: white-tailed deer in Finland. Ann Zool Fenn. 2016;53:69-80. https:/ / doi.org/10.5735/ 086.053.0206

38. Uusitalo R, Siljander M, Dub T, Sane J, Sormunen JJ, Pellikka P, et al. Modelling habitat suitability for occurrence of human tick-borne encephalitis (TBE) cases in Finland. Ticks Tick Borne Dis. 2020;11:101457. https:/ / doi.org/ 10.1016/j.ttbdis.2020.101457

39. Huang C-I, Kay SC, Davis S, Tufts DM, Gaffett K, Tefft B, et al. High burdens of Ixodes scapularis larval ticks on white-tailed deer may limit Lyme disease risk in a low biodiversity setting. Ticks Tick Borne Dis. 2019;10:258-68. https://doi.org/10.1016/j.ttbdis.2018.10.013

40. Tonteri E, Jokelainen P, Matala J, Pusenius J, Vapalahti O. Serological evidence of tick-borne encephalitis virus infection in moose and deer in Finland: sentinels for virus circulation. Parasit Vectors. 2016;9:54. https:/ / doi.org/10.1186/s13071016-1335-6

41. Suchomel J. Non-native mammal species in the Czech Republic. Zooreport. 2015 [cited 2019 May 6]. https:/ / www. zoobrno.cz/img/UK\%20ZOO\%20profi \%20PROSINEC\%20 2015\%20K02.pdf

42. Morgenstern H. Ecologic studies in epidemiology: concepts, principles, and methods. Annu Rev Public Health. 1995;16:61-81. https:// doi.org/10.1146/annurev. pu.16.050195.000425

43. University of Helsinki. VECLIMIT: vector-borne diseases and climate change in Finland: mapping, modelling, mitigation. 2020 [cited 2020 Jun 28]. https:/ / www.helsinki.fi/en/ projects/veclimit

Address for correspondence: Timothée Dub, Department of Health Security, Finnish Institute for Health and Welfare, Mannerheimintie 166 Helsinki 00271, Helsinki, Finland; email: timothee.dub@thl.fi 